\title{
Uniform Fe304 microflowers hierarchical structures assembled with porous nanoplates as superior anode materials for lithium-ion batteries
}

Wang, Xiaoliang; Liu, Yanguo; Arandiyan, Hamidreza; Yang, Hongping; Bai, Lu; Mujtaba, Jawayria; Wang, Qingguo; Liu, Shanghe; Sun, Hongyu

\section{Published in:}

Applied Surface Science

Link to article, DOI:

10.1016/j.apsusc.2016.07.105

Publication date:

2016

Document Version

Peer reviewed version

Link back to DTU Orbit

Citation $(A P A)$ :

Wang, X., Liu, Y., Arandiyan, H., Yang, H., Bai, L., Mujtaba, J., Wang, Q., Liu, S., \& Sun, H. (2016). Uniform $\mathrm{Fe}_{2} \mathrm{O}$ microflowers hierarchical structures assembled with porous nanoplates as superior anode materials for lithium-ion batteries. Applied Surface Science, 389, 240-246. https://doi.org/10.1016/j.apsusc.2016.07.105

\section{General rights}

Copyright and moral rights for the publications made accessible in the public portal are retained by the authors and/or other copyright owners and it is a condition of accessing publications that users recognise and abide by the legal requirements associated with these rights.

- Users may download and print one copy of any publication from the public portal for the purpose of private study or research.

- You may not further distribute the material or use it for any profit-making activity or commercial gain

- You may freely distribute the URL identifying the publication in the public portal 


\section{Uniform $\mathrm{Fe}_{3} \mathrm{O}_{4}$ microflowers hierarchical structures assembled with porous nanoplates as superior anode materials for lithium-ion batteries}

Xiaoliang Wang ${ }^{\text {a }}$, Yanguo Liu ${ }^{\mathrm{b}}$, Hamidreza Arandiyan ${ }^{\mathrm{c}}$, Hongping Yang ${ }^{\mathrm{d}}$, Lu Bai ${ }^{\mathrm{d}}$, Jawayria Mujtaba $^{\mathrm{d}}$, Qingguo Wang ${ }^{\text {a }}$, Shanghe Liu ${ }^{\text {a }}$, Hongyu Sun ${ }^{\mathrm{d}, \mathrm{e}, \text { * }}$

${ }^{\mathrm{a}}$ Institute of Electrostatic \& Electromagnetic Protection, Mechanical Engineering College, Shijiazhuang 050003, China

b School of Resources and Materials, Northeastern University at Qinhuangdao, Qinhuangdao 066004, China

c Particles and Catalysis Research Group, School of Chemical Engineering, The University of New South Wales, Sydney, New South Wales 2052, Australia

${ }^{\mathrm{d}}$ Beijing National Center for Electron Microscopy, School of Materials Science and Engineering, Tsinghua University, Beijing 100084, China

e Department of Micro- and Nanotechnology, Technical University of Denmark, 2800 Kongens Lyngby, Denmark

${ }^{*}$ Corresponding author. E-mail address: hyltsun@gmail.com, hsun@nanotech.dtu.dk (H. Sun) 


\section{ABSTRACT}

Uniform $\mathrm{Fe}_{3} \mathrm{O}_{4}$ microflowers assembled with porous nanoplates were successfully synthesized by a solvothermal method and subsequent annealing process. The structural and compositional analysis of the $\mathrm{Fe}_{3} \mathrm{O}_{4}$ microflowers were studied by X-ray diffraction (XRD), scanning electron microscopy (SEM), transmission electron microscopy (TEM), and X-ray photoelectron spectroscopy (XPS). The Bruauer-Emmett-Teller (BET) specific surface area was calculated by the nitrogen isotherm curve and pore size distribution of $\mathrm{Fe}_{3} \mathrm{O}_{4}$ microflowers was determined by the Barret-Joyner-Halenda (BJH) method. When evaluated as anode material for lithium-ion batteries, the as-prepared $\mathrm{Fe}_{3} \mathrm{O}_{4}$ microflowers electrodes delivered superior capacity, better cycling stability and rate capability than that of $\mathrm{Fe}_{3} \mathrm{O}_{4}$ microspheres electrodes. The improved electrochemical performance was attributed to the microscale flowerlike architecture and the porous sheet structural nature.

Keywords: $\mathrm{Fe}_{3} \mathrm{O}_{4}$; anode; microflowers; nanoplates; lithium-ion batteries 


\section{Introduction}

Rechargeable lithium-ion batteries (LIBs), which have been widely used in flexible electronics, mobile phones, and laptop computers, are one of the great successes of modern materials electrochemistry [1, 2]. Recently, high-performance LIBs with higher capacity, longer cycle life, and better rate capability have attracted considerable responsiveness for the use in electric vehicle market and as energy source of large industrial equipment etc [3, 4]. Developing advanced electrode materials is a key element to achieve the required performance and capacity of LIBs for the above important applications, since the overall performance of LIBs is highly dependent on the inherent electrochmical properties of the electrode materials [5, 6]. Therefore, considerable attention has been paid to develop novel materials for both the cathodes and anodes of LIBs which are inexpensive, safe and environmentally benign. So far, graphitic/non-graphitic carbon [7, 8], transition-metal oxides [9, 10], nitrides [11, 12], alloys [13-15] and their composites have been exploited as the anode materials of LIBs. In this context, transition metal oxides have received special intersest since they can exhibit about three times higher capacity than the commerial used graphite with a capacity of $372 \mathrm{mAh} \mathrm{g}^{-1}$.

As a typical transition metal oxide, $\mathrm{Fe}_{3} \mathrm{O}_{4}$ has gained considerable attention for future LIB anodes due to its natural abundance, low cost, environmental benignity, high electronic conductivity as well as high theoretical capacity (926 $\mathrm{mAh} \mathrm{g}^{-1}$ ) [16] according to the electrochemical conversion reaction $\mathrm{Fe}_{3} \mathrm{O}_{4}+8 \mathrm{Li}^{+}+8 \mathrm{e}^{-} \leftrightarrow 3 \mathrm{Fe}+4 \mathrm{Li}_{2} \mathrm{O}$ [17]. Thermodynamically, the formation of electrochemically inactive $\mathrm{Li}_{2} \mathrm{O}$ is favorable during the first discharge process. However, the extraction of $\mathrm{Li}^{+}$ion from $\mathrm{Li}_{2} \mathrm{O}$ in the charge process is difficult, making the conversion reaction is irreversible to some extent [18-20]. Moreover, the weakness of $\mathrm{Fe}_{3} \mathrm{O}_{4}$ as 
anode materials also lies in the large volume expansion and severe particle aggregation durng the charging and discharging process, resulting in the deterioration of reversible capacity and poor cycling stability [21, 22]. The results are common for transition metal oxide anode materials and are one of the major obstacles for this new category of materials to be commercialized.

Design and synthesis of electrode materials with reasonable composition, morphology, and microstructure is reliable to overcome the above limitations and improve the LIB performance. For example, Pan et al reported a hybridization strategy for the co-assembly of $\mathrm{Fe}_{3} \mathrm{O}_{4}$ nanoparticles and $\mathrm{TiO}_{2}$ nanorods on pristine graphene nanosheets hierarchical nanostructures [23]. The ternary heterostructures delivered superior reversible capacities and rate capabilities. Chen et al synthesized porous hollow $\mathrm{Fe}_{3} \mathrm{O}_{4}$ beads constructed with nanorods through solvothermal route [20]. The products showed a reversible specific capacity of $500 \mathrm{mAhg}^{-1}$ after 50 cycles at a current density of $100 \mathrm{mAg}^{-1}$. Wang and co-workers studied the effect of Co-doping on the electrochemical performance, and found that the solid solution $\mathrm{Co}_{x} \mathrm{Fe}_{3 \chi} \mathrm{O}$ showed excellent cycle stability and rate performance [24]. Coating the electrochemically active materials with an electronically conductive agents layer, which modify the chemistry at the electrode/electrolyte interface, is considered as another effective approach to improve the cycling stability and rate capability [25-28]. Such coating not only facilitates the formation of a stable solid electrolyte interphase (SEI) layer on the electrode surface, but also enhances the electrode kinetics through conductivity improvements [29]. However, the addition of conductive agents unavoidably decreases the effective use of active materials. On the other hand, various in-situ techniques (such as in-situ x-ray diffraction/tomography [30] and in-situ transmission electron microscopy [31, 32]) are employed to investigate the complex phase transition, structural evolution and fundamental 
mechanisms of electrode materials during the electrochemical reaction.

Complex hierarchical architectures assembled by low-dimensional nano building blocks possess enhanced LIB performance [33, 34]. We have reported a facile synthesis of hierarchical porous $\mathrm{Co}_{3} \mathrm{O}_{4}$ nanostructures with morphologies including hierarchical nanoflowers and hyperbranched nano bundles, which were all built up by numerous nanoparticles with random attachment [35]. When evaluated as anode materials for LIBs, the nanoflowers showed higher capacity and better rate capability. Wang et al developed a simple ethylenediamine-mediated solvothermal followed by decomposition at high temperature to synthesis $\mathrm{Fe}_{3} \mathrm{O}_{4}$ hollow microspheres, which were assembled by nanoplate building blocks [18]. The electrochemical characterization showed significantly improved lithium-storage capabilities with a very high reversible capacity of $580 \mathrm{mAhg}^{-1}$ at a current density of $200 \mathrm{mAg}^{-1}$ after 100 cycles.

In this work, we report a facile solvothermal and subsequent annealing method for the construction of uniform $\mathrm{Fe}_{3} \mathrm{O}_{4}$ microflowers. Microstructure characterizations showed that the microflowers were assembled by porous nanoplates as nano building blocks. The unique hierarchical nanostructures would enhance their physical/chemical properties while inheriting merits of the primary subunits. For example, the porous nanoplates can ensure short transport length for $\mathrm{Li}^{+}$ions and electrons, the microscale flower architecture is favored for preventing the aggregation of the nano/microcrystals, and the porous $\mathrm{Fe}_{3} \mathrm{O}_{4}$ microflowers can provide extra active sites for the storage of ions. When evaluated as anode materials for $\mathrm{LIBs}$, the $\mathrm{Fe}_{3} \mathrm{O}_{4}$ microflowers exhibited high reversible capacity and excellent cycling performance. It is also anticipated that the present $\mathrm{Fe}_{3} \mathrm{O}_{4}$ hierarchical architectures will find potential applications in other energy storage system when considering the similar microstructure design principles with LIBs. 


\section{Experimental}

\subsection{Materials synthesis}

All of the chemical reagents were of analytical grade and used as received without further purification. For the synthesis of the $\mathrm{Fe}_{3} \mathrm{O}_{4}$ microflowers assembled with porous nanoplates, anhydrous ferric chloride $\left(\mathrm{FeCl}_{3}, 10 \mathrm{mmol}\right)$ was dissolved in ethylene glycol $(80 \mathrm{ml})$ to form a clear solution, followed by the addition of urea $(80 \mathrm{mmol})$. The mixture was stirred vigorously for 30 min until it became homogeneous and then sealed in a $100 \mathrm{ml}$ Teflon-lined stainless-steel autoclave at $200{ }^{\circ} \mathrm{C}$ for $4 \mathrm{~h}$. After cooling to room temperature naturally, a green precursor was obtained by centrifuging and sequentially rinsing with water and ethanol for several times, and then dried in a vacuum oven at $60{ }^{\circ} \mathrm{C}$ overnight. The final products were obtained by heating the precursor powder in $\mathrm{N}_{2}$ atmosphere to $400{ }^{\circ} \mathrm{C}$ at a rate of $8{ }^{\circ} \mathrm{C} \min ^{-1}$ and maintaining at this temperature for $1.5 \mathrm{~h}$.

\subsection{Structural characterization}

The morphology, composition and crystal structure of the products were examined by employing field-emission scanning electron microscope (FESEM; Zeiss, MERLIN, $5 \mathrm{kV}$ ), transmission electron microscope equipped with an energy dispersive X-ray (EDX) system (TEM; JEOL, JEM-2100, 200 kV; FEI, Tecnai G² 20, 200 kV), X-ray photoelectron spectroscopy (XPS, Escalab 250, Al $\mathrm{K} \alpha$ ), and Raman spectrometer (Renishaw, UK, $633 \mathrm{~nm}$ excitation). Crystallographic information for the samples was collected using a Bruker Model D8 Advance powder X-ray diffractometer (XRD) Cu $K_{\alpha}$ irradiation $(\lambda=1.5418 \AA$ ). The Bruauer-Emmett-Teller (BET) surface area of the powders was analyzed by nitrogen adsorption-desorption isotherm at 77 $\mathrm{K}$ in a Micromeritics ASAP 2010 system. The sample was degassed at $180{ }^{\circ} \mathrm{C}$ before nitrogen 
adsorption measurements. The surface area was determined by a multipoint BET method. A desorption isotherm was used to determine the pore size distribution via the Barret-Joyner-Halender (BJH) method, assuming a cylindrical pore model. The nitrogen adsorption volume at the relative pressure $\left(P / P_{0}\right)$ of 0.994 was used to determine the pore volume and average pore size. In order to study the morphology and structure of the $\mathrm{Fe}_{3} \mathrm{O}_{4}$ microflowers after cycling test, the coin cells were disassembled in Argon atmosphere, and then the electrodes were gently rinsed with anhydrous di-methyl carbonate (DMC) to remove residual carbonate solvents and $\mathrm{LiPF}_{6}$ salt several times, followed by vacuum drying overnight at room temperature.

\subsection{Electrochemical Measurements}

To measure the electrochemical performance, electrodes were constructed by mixing the active materials, conductive carbon black and carboxymethyl cellulose, in a weight ratio of 80:10:10. The mixture was prepared as slurry and spread onto copper foil (the typical loading of the active material is in the range of 3.2-4.5 $\mathrm{mgcm}^{-2}$ ). The electrode was dried under vacuum at $120{ }^{\circ} \mathrm{C}$ for $5 \mathrm{~h}$ to remove the solvent before pressing. Then the electrodes were cut into disks (12 $\mathrm{mm}$ in diameter) and dried at $100{ }^{\circ} \mathrm{C}$ for $24 \mathrm{~h}$ in vacuum. The cells were assembled inside an Ar-filled glove box by using a lithium metal foil as the counter electrode and the reference electrode and microporous polypropylene as the separator. The electrolyte used was $1 \mathrm{M} \mathrm{LiPF}_{6}$ dissolved in a mixture of ethylene carbonate (EC), propylene carbonate (PC), and diethyl carbonate (DEC) with a volume ratio of EC/PC/DEC = 3:1:1. Assembled cells were allowed to soak overnight, and then electrochemical tests on a LAND battery test unit were performed. Galvanostatic charge and discharge of the assembled cells were performed at a current density of $100 \mathrm{mAg}^{-1}$ between voltage limits of 0.05 and $3 \mathrm{~V}\left(\mathrm{vs} . \mathrm{Li}^{+} / \mathrm{Li}\right.$ ) for 50 cycles. For the high rate tests, 
the discharge current gradually increased from $50 \mathrm{mAg}^{-1}$ to 100,500 and $1000 \mathrm{mAg}^{-1}$, and then decreased to $50 \mathrm{mAg}^{-1}$, step by step. All the charge/discharge tests were performed symmetrically at room temperature. The cyclic voltammogram (CV) was performed using a CHI 660D electrochemical workstation (Chenhua Instrument, Shanghai). CV curves were recorded between 0.05 and $3.00 \mathrm{~V}\left(\mathrm{vs} . \mathrm{Li}^{+} / \mathrm{Li}\right)$ at a scan rate of $0.5 \mathrm{mV} \mathrm{s}^{-1}$. Electrochemical impedance spectroscopy (EIS, IM6, Zahner) was carried out by applying an AC voltage of $5 \mathrm{mV}$ over a frequency range of $100 \mathrm{kHz}$ to $0.01 \mathrm{~Hz}$.

\section{Results and discussion}

The crystallographic structure and phase purity of the as prepared products were characterized by using XRD analysis. Fig. 1 shows a typical XRD pattern of the sample synthesized by solvothermal reaction and subsequent annealing process. All the diffraction peaks can be assigned to (220), (311), (400), (422), (511), (440), and (533) planes of $\mathrm{Fe}_{3} \mathrm{O}_{4}$ with inverse spinel structure (JCPDS No. 19-0629, a= $8.396 \AA$ ). No other diffraction peaks from possible impurities are observed, indicating the high phase purity of the products. Moreover, the relatively high peak intensities imply that the products are highly crystalline. The average crystallite sizes $(d)$ of $\mathrm{Fe}_{3} \mathrm{O}_{4}$ phase can be calculated from the physical breadths of the corresponding diffraction peak as expressed by the Scherrer formula: $d=0.89 \lambda / \beta \cos \theta$, where $\lambda$ is the X-ray wavelength, $\beta$ is the full width at half maximum of the diffraction peak, and $\theta$ is the diffraction angle [36]. Here, the crystallite size was calculated using the (311) peak. The obtained crystallite sizes is about $9.6 \mathrm{~nm}$, this will be further confirmed by FESEM and TEM observations as discussed later.

Fig. 2a illustrates a typical low-magnification FESEM image of the final product which consists of microspheres uniformly distributed on the substrate. The diameter of the microsphere 
ranges from $\sim 3$ to $\sim 6 \mu \mathrm{m}$. Higher magnification images (Fig. 2b, c) indicate that the microspheres present flower-like morphology characteristic, which is in agreement with that of the precursor (Fig. S1). The microflowers consist of two dimensional nanoplates with an average thickness $\sim 60$ nm. In addition, the coarse surface of the nanoplates suggests a highly porous texture (Fig. 2d).

More structural details of the $\mathrm{Fe}_{3} \mathrm{O}_{4}$ microflowers were studied by employing TEM and HRTEM characterizations. Fig. 3a-e show typical TEM images of $\mathrm{Fe}_{3} \mathrm{O}_{4}$ microflowers with different magnifications. The building blocks of the hierarchical microflowers are highly porous nanoplates, which are consistent with the FESEM observations. We also find that the porous nanoplates consist of interconnected nanoparticles with average size of $\sim 10 \mathrm{~nm}$ (Fig. 3d, e). EDX result (Fig. S2) shows that the microflowers are composed of Fe and O, and the atomic ratio is 3:4 for element Fe to element $\mathrm{O}$, also confirming the formation of $\mathrm{Fe}_{3} \mathrm{O}_{4}$. Corresponding EDX elemental mapping indicates the uniform distribution of $\mathrm{Fe}$ and $\mathrm{O}$ across the porous nanoplates (Fig. S3). The selected area electron diffraction (SAED) pattern indicates that the as obtained $\mathrm{Fe}_{3} \mathrm{O}_{4}$ microflowers are polycrystal in nature as shown in the inset of Fig. 3d (see also the enlarged view shown in Fig. S4). Fig. 3f shows a typical HRTEM image of a single $\mathrm{Fe}_{3} \mathrm{O}_{4}$ nanoplate from the microflowers. The lattice spacings of $d \sim 3.01 \AA$ and $\sim 4.88 \AA$ are determined, which correspond to the (220) and (111) planes of cubic $\mathrm{Fe}_{3} \mathrm{O}_{4}$, respectively. The measured angle between the (220) and (111) planes is $90^{\circ}$, in agreement with the theoretical value. All results clearly demonstrate that we have succeeded in obtaining $\mathrm{Fe}_{3} \mathrm{O}_{4}$ microflowers assembled with mesoporous nanoplates. To investigate the formation process of the $\mathrm{Fe}_{3} \mathrm{O}_{4}$ microflowers, a series of time-dependent morphological evolution experiments for the precursors and annealed products were performed as shown in Fig. S5. For the precursors, at the early stage of the reaction (15 min), 
the sample was composed of $\sim 100 \mathrm{~nm}$ particles and nanoplates with smooth surface (Fig. S5 top, a and g). After 30 min reaction, the smooth nanoplates assembled into a multilayer and network structure, resulting in the formation of the hierarchical microflowers (Fig. S5 top, b and h). At the same time, the amount of the nanoparticles decreased. As the reaction time was prolonged to $1 \mathrm{~h}$, the sample was composed entirely of the microflowers and no nanoparticles remained (Fig. S5 top, c and i). Further increasing the reaction time to $2 \mathrm{~h}, 3 \mathrm{~h}$, and $4 \mathrm{~h}$, the flowerlike character of the precursors remained nearly unchanged. Subsequent annealing did not change the morphology very much except that the nanoplates were coarse and porous (Fig. S5 bottom). Based on the observations described above, a possible formation mechanism of the microflowers is proposed. When aqueous solution containing $\mathrm{Fe}^{3+}$ is mixed with ethylene glycol and urea, the initial burst nucleation occurs, which leads to the aggregation of the supersaturated nuclei and formation of nanoparticles. Those particles then assemble into smooth nanoplates due to Ostwald ripening [37]. Meanwhile, the nanoplates crosslinked together in order to decrease the system energy, and the microflowers are formed consequently. Similar hierarchical flowerlike nanostructures were also reported elsewhere [38].

The surface elemental composition and oxidation state of the microflowers were analyzed by using XPS in the region of 0-1350 eV. The survey spectrum (Fig. 4a) indicates that the sample contains Fe and O. Fig. 4b shows the high-resolution XPS spectra of Fe 2p region, which can be fitted with two spin-orbit doublets and a shakeup satellite. The doubles are characteristic of the peaks of $\mathrm{Fe}^{2+}$ and $\mathrm{Fe}^{3+}$. The results are consistent with the reported values of $\mathrm{Fe}_{3} \mathrm{O}_{4}[23,39,40]$. As shown in Fig. 4c, the $\mathrm{O}$ 1s spectrum could be deconvoluted into two peaks at 530.27 and $531.55 \mathrm{eV}$. The peak at $530.27 \mathrm{eV}$ is a typical state of $\mathrm{Fe}-\mathrm{O}$ species corresponding to $\mathrm{Fe}_{3} \mathrm{O}_{4}$, while 
the other peak could be attributed to the presence of residual oxygen-containing groups (such as O-H) in the sample [41]. The Raman bands ranged from 100 to $800 \mathrm{~cm}^{-1}$ can be assigned to the vibration modes of ferrites (Fig. S6) [42]. The results also confirm the formation of $\mathrm{Fe}_{3} \mathrm{O}_{4}$ phase. The pore structure information, including specific surface area and the porous feature, of the $\mathrm{Fe}_{3} \mathrm{O}_{4}$ microflowers were studied by measuring nitrogen adsorption-desorption isotherms at $77 \mathrm{~K}$ (Fig. 4d). The BET specific surface area is as high as $114.9 \mathrm{~m}^{2} \mathrm{~g}^{-1}$. In addition, the narrow mesopore size distribution based on the BJH method of the sample is further confirmed by the corresponding pore size distribution curve (the inset in Fig. 4d). The large surface area and narrow pore size distribution of the sample are due to the porous nature of the assembled nanoplates and the amount of void spaces between the interconnected nanoparticles within each plate. For comparison, the microstructure (Figs. S7, 8) and pore structures (Fig. S9) of $\mathrm{Fe}_{3} \mathrm{O}_{4}$ microspheres are also tested. The BET specific surface area is $86.6 \mathrm{~m}^{2} \mathrm{~g}^{-1}$, which is smaller than that of microflowers. Pore size distribution result implies the existence of mesopore in the microspheres. The microstructure characteristics of the yielded $\mathrm{Fe}_{3} \mathrm{O}_{4}$ microflowers are favorable for using as anode materials in LIBs due to the capability of providing extra active sites for the storage of lithium ions and facilitating mass diffusion and ion transport. The synthesized sample is therefore anticipated to show good lithium-storage properties.

We subsequently investigate the electrochemical lithium-storage properties of the as-prepared $\mathrm{Fe}_{3} \mathrm{O}_{4}$ microflowers. The electrochemical behavior of the assembled cells was first investigated by CV experiments between 0.05 and $3 \mathrm{~V}$ (vs. $\mathrm{Li}^{+} / \mathrm{Li}$ ) at a scan rate of $0.5 \mathrm{mVs}^{-1}$, using the $\mathrm{Fe}_{3} \mathrm{O}_{4}$ microflowers as the working electrode and a lithium sheet as both counter electrode and reference electrode. Fig. 5a shows the $\mathrm{CV}$ curves of $\mathrm{Fe}_{3} \mathrm{O}_{4}$ microflowers for the first three cycles. In the first 
cycle, the cathodic peak at $1.01 \mathrm{~V}$ corresponds to the forming $\mathrm{Li}_{x} \mathrm{Fe}_{3} \mathrm{O}_{4}$, while the peak at $0.65 \mathrm{~V}$ is due to the formation of SEI film and $\mathrm{Li}_{2} \mathrm{O}$. The anodic peaks at $1.67 \mathrm{~V}$ and $1.94 \mathrm{~V}$ are attributed to the reversible oxidation from $\mathrm{Fe}^{0}$ to $\mathrm{Fe}^{3+}$. The redox peaks in the $\mathrm{CV}$ curves are in good agreement with the previous reports [40]. In the subsequent cycles, the CV curves overlap very well, indicating high electrochemical reversibility.

The charge-discharge voltage profiles of the $\mathrm{Fe}_{3} \mathrm{O}_{4}$ microflowers for the first three cycles at a current rate of $100 \mathrm{mAg}^{-1}$ is shown in Fig. 5b. In the first discharge curve, there is a dominant potential plateau $(\sim 0.75 \mathrm{~V})$ and a following slope, which represents lithium ion insertion process, and the formation of SEI film, respectively. The initial charge and discharge capacities of $\mathrm{Fe}_{3} \mathrm{O}_{4}$ microflowers are 1084.1 and $1365.4 \mathrm{mAhg}^{-1}$, yielding the Coulombic efficiency values (the ratio of charge capacity to discharge capacity) of $79.4 \%$. Such initial irreversible capacity loss should mainly originate the formation of SEI layer due to the irreversible degradation of electrolyte and other secondary reactions, which is common for transition metal compound anode materials [18, 43-45]. In the second and third cycles the $\mathrm{Fe}_{3} \mathrm{O}_{4}$ microflowers electrode presents much better electrochemical reversibility. Fig. 5c shows the charge-discharge cycling performance together with the Coulombic efficiency at a current density of $100 \mathrm{mAg}^{-1}$. From the second cycle onwards, the as-prepared $\mathrm{Fe}_{3} \mathrm{O}_{4}$ microflowers exhibit excellent cyclic capacity retention with a stable capacity $\sim 1080.9 \mathrm{mAhg}^{-1}$. At the end of 50 charge-discharge cycles, a reversible capacity $\sim 1000.3$ mAhg ${ }^{-1}$ can still be retained. In contrast, the reversible capacity of $\mathrm{Fe}_{3} \mathrm{O}_{4}$ microspheres cell decreases to $\sim 305.3 \mathrm{mAhg}^{-1}$ after 50 cycles of operation. Fig. 5d shows the electrochemical performance of $\mathrm{Fe}_{3} \mathrm{O}_{4}$ microflowers and microspheres at various rates between 50 and $1000 \mathrm{mAg}^{-1}$. The reversible capacity of the $\mathrm{Fe}_{3} \mathrm{O}_{4}$ microflowers cell varies from $1300 \mathrm{mAhg}^{-1}$ to $840 \mathrm{mAhg}^{-1}$ at 
current rates of $50 \mathrm{mAg}^{-1}$ and $1000 \mathrm{mAg}^{-1}$, respectively. Nevertheless, the reversible capacity of the $\mathrm{Fe}_{3} \mathrm{O}_{4}$ microspheres cell rapidly drops from 1028 to $286 \mathrm{mAhg}^{-1}$. $\mathrm{Fe}_{3} \mathrm{O}_{4}$ microflowers cell recovers its original capacity ( $1285 \mathrm{mAhg}^{-1}$ for the $50^{\text {th }}$ cycle) when the rate return to the initial $50 \mathrm{mAg}^{-1}$. These results demonstrate that the $\mathrm{Fe}_{3} \mathrm{O}_{4}$ microflowers electrode possesses good electrochemical reversibility. The transfer behavior of lithium ions in $\mathrm{Fe}_{3} \mathrm{O}_{4}$ microflowers and microspheres electrode was analyzed based on EIS spectra (Fig. S10). The Nyquist plots in the frequency range from $100 \mathrm{kHz}$ to $0.01 \mathrm{~Hz}$ consist of a slope at the low frequencies connected to a depressed semicircle at the medium to high frequencies, representing the lithium diffusion process inside the electrode material, and the charge-transfer resistance $\left(R_{c t}\right)$ on electrolyte and the electrode interface, respectively [46-48]. The diameter of the $\mathrm{Fe}_{3} \mathrm{O}_{4}$ microflowers is found to be much smaller than that of $\mathrm{Fe}_{3} \mathrm{O}_{4}$ microspheres, revealing that the $\mathrm{R}_{\mathrm{ct}}$ value is smaller for $\mathrm{Fe}_{3} \mathrm{O}_{4}$ microflowers [46-48]. The mesoporous structure on the $\mathrm{Fe}_{3} \mathrm{O}_{4}$ microflowers, which can reduce the effective distance for lithium ions and electrons transport, is responsible for decreasing the $\mathrm{R}_{\mathrm{ct}}$ value and thus benefiting the diffusion kinetics upon cycling. The morphology and structure of the $\mathrm{Fe}_{3} \mathrm{O}_{4}$ microflowers after rate capability test (50 cycles) were characterized by SEM and TEM observations (Fig. S11). It can be seen that the sample still maintains the initial flower-like morphology with porous nanoplates as the nano building blocks. The results reveal the good structural and morphological stabilities of $\mathrm{Fe}_{3} \mathrm{O}_{4}$ microflowers during charge/discharge cycling. In addition, the lithium storage properties of $\mathrm{Fe}_{3} \mathrm{O}_{4}$ microflower electrodes outperform or can compare with other $\mathrm{Fe}_{3} \mathrm{O}_{4}$ nanoparticles, hierarchical structures and even some $\mathrm{Fe}_{3} \mathrm{O}_{4} / \mathrm{C}$ nanocomposites reported elsewhere (Table S1). Although for some cases, such as yolk-shelled $\mathrm{Fe}_{3} \mathrm{O}_{4} @$ carbon [49] and $\mathrm{Fe}_{3} \mathrm{O}_{4} /$ graphene sheet composite [40], the current $\mathrm{Fe}_{3} \mathrm{O}_{4}$ microflower 
results are not very satisfactory. It would be anticipated that better LIB performance can be obtained when combining the present flowerlike architectures with other modification techniques (compositing, doping, etc).

The above electrochemical measurements indicate the good lithium-storage properties of the $\mathrm{Fe}_{3} \mathrm{O}_{4}$ microflowers in terms of cycling stability, specific capacity, and rate capability, which can be attributed to the following reasons. (1) The microscale flower architecture assembled with porous nanoplates is favored for preventing the aggregation of the nano/microcrystals, which is of importance for the cycling stability. Moreover, the porous nanoplates can accommodate the local volume change during charge/discharge cyclings and are able to alleviate the problem of pulverization and aggregation of the electrode material, which are also favorable for improving the cycling performance. (2) The porous $\mathrm{Fe}_{3} \mathrm{O}_{4}$ microflowers can provide extra active sites for the storage of lithium ions, which is beneficial for increasing the specific capacity. (3) The porous $\mathrm{Fe}_{3} \mathrm{O}_{4}$ microflowers can reduce the effective distance for lithium ions and electrons transport, and mass diffusion, resulting in good rate capabilities.

\section{Conclusion}

In summary, uniform $\mathrm{Fe}_{3} \mathrm{O}_{4}$ microflowers assembled by porous nanoplates were successfully synthesized by a facile solvothermal and subsequent annealing method. When used as the anode materials for LIB, the as-prepared sample delivered good lithium storage properties in terms of cycling stability, specific capacity, and rate capability. Specifically, the $\mathrm{Fe}_{3} \mathrm{O}_{4}$ microflowers showed a high reversible capacity of $\sim 1000 \mathrm{mAhg}^{-1}$ after 50 cycles at a current density of 100 $\mathrm{mAg}^{-1}$. A capacity of $840 \mathrm{mAhg}^{-1}$ was still achieved at $1000 \mathrm{mAg}^{-1}$. It is believed that the superior electrochemical performance mainly attribute to the microscale flower architecture and the porous 
sheet structural nature. The present route to porous $\mathrm{Fe}_{3} \mathrm{O}_{4}$ microflowers can also be extended to synthesis other metal oxides with similar morphology and enhanced functions.

\section{Acknowledgments}

The authors would like to appreciate the financial supports from Chinese National Natural Science Foundation (51401114, 51571054) and China Postdoctoral Science Foundation (2013M542528). This work made use of the resources of the Beijing National Center for Electron Microscopy.

\section{References}

[1] J.B. Goodenough, A. Manthiram, A perspective on electrical energy storage, MRS Commun. 4 (2014) 135-142.

[2] V.L. Pushparaj, M.M. Shaijumon, A. Kumar, S. Murugesan, L.J. Ci, R. Vajtai, R.J. Linhardt, O. Nalamasu, P.M. Ajayan, Flexible energy storage devices based on nanocomposite paper, Proc. Natl. Acad. Sci. USA 104 (2007) 13574-13577.

[3] C. Liu, F. Li, L. P. Ma, H.M. Cheng, Advanced materials for energy storage, Adv. Mater. 22 (2010) 28-62.

[4] Y.G. Guo, J.S. Hu, L.J. Wan, Nanostructured materials for electrochemical energy conversion and storage devices, Adv. Mater. 20 (2008) 2878-2887.

[5] S. Goriparti, E. Miele, F. De Angelis, E. Di Fabrizio, R.P. Zaccaria, C. Capiglia, Review on recent progress of nanostructured anode materials for Li-ion batteries, J. Power Sources 257 (2014) 421-443.

[6] N.S. Choi, Z.H. Chen, S.A. Freunberger, X.L. Ji, Y.K. Sun, K. Amine, G. Yushin, L.F. Nazar, J. Cho, P. G. Bruce, Challenges facing lithium batteries and electrical double-layer capacitors, Angew. Chem. Int. Ed. 51 (2012) 9994-10024.

[7] R.I.R Blyth, H Buqa, F.P Netzer, M.G Ramsey, J.O Besenhard, P Golob, M Winter, XPS studies of graphite electrode materials for lithium ion batteries, Appl. Surf. Sci. 167 (2000) 99-106.

[8] M. Yoshio, H.Y. Wang, K. Fukuda, T. Umeno, T. Abeb, Z.Ogumi, Improvement of natural 
graphite as a lithium-ion battery anode material, from raw flake to carbon-coated sphere, J. Mater. Chem. 14 (2004) 1754-1758.

[9] P. Poizot, S. Laruelle, S. Grugeon, L. Dupont, J.M. Tarascon, Nano-sized transition-metal oxides as negative-electrode materials for lithium-ion batteries, Nature 407 (2000) 496-499.

[10] L.L. Gu, W.H. Xie, S. Bai, B.L. Liu, S. Xue, Q. Li, D.Y. He, Facile fabrication of binder-free NiO electrodes with high rate capacity for lithium-ion batteries, Appl. Surf. Sci. 368 (2016) 298-302.

[11] Y.T. Gong, M.M. Li, Y. Wang, Carbon nitride in energy conversion and storage: recent advances and future prospects, ChemSusChem 8 (2015) 931-946.

[12] M.S. Balogun, W.T. Qiu, W. Wang, P.P. Fang, X.H. Lu, Y.X. Tong, Recent advances in metal nitrides as high-performance electrode materials for energy storage devices, J. Mater. Chem. A 3 (2015) 1364-1387.

[13] G.W. Zhou, H. Li, H.P. Sun, D.P. Yu, Y.Q. Wang, X.J. Huang, L.Q. Chen, Z. Zhang, Controlled Li doping of Si nanowires by electrochemical insertion method, Appl. Phys. Lett. 75 (1999) 2447-2449.

[14] K.H. Seng, M.H. Park, Z.P. Guo, H.K. Liu, J. Cho, Self-assembled germanium/carbon nanostructures as high-power anode material for the lithium-ion battery, Angew. Chem. Int. Ed. 51 (2012) 5657-5661.

[15] X.K. Huang, S.M. Cui, J.B. Chang, P.B. Hallac, C.R. Fell, Y.T. Luo, B. Metz, J.W. Jiang, P.T. Hurley, J.H. Chen, Hierarchical tin/carbon composite as an anode for lithium-ion batteries with a long cycle life, Angew. Chem. Int. Ed. 54 (2014) 1490-1493.

[16] M.V. Reddy, G.V. Subba Rao, B.V.R. Chowdari, Metal oxides and oxysalts as anode materials for li ion batteries, Chem. Rev. 113 (2013) 5364-5457.

[17] T. Muraliganth, A.V. Murugan, A. Manthiram, Facile synthesis of carbon-decorated single-crystalline Fe3O4nanowires and their application as high performance anode in lithium ion batteries, Chem. Commun. 2009, 7360-7362.

[18] B. Wang, H.B. Wu, L. Zhang, X.W. Lou, Self-supported construction of uniform $\mathrm{Fe}_{3} \mathrm{O}_{4}$ hollow microspheres from nanoplate building blocks, Angew. Chem. Int. Ed. 52 (2013) 4165-4168. 
[19] Z. Xiao, Y. Xia, Z.H. Ren, Z.Y. Liu, G. Xu, C.Y. Chao, X. Li, G. Shen, G.R. Han, Facile synthesis of single-crystalline mesoporous $\alpha-\mathrm{Fe}_{2} \mathrm{O}_{3}$ and $\mathrm{Fe}_{3} \mathrm{O}_{4}$ nanorods as anode materials for lithium-ion batteries, J. Mater. Chem. 22 (2012) 20566-20573.

[20] Y. Chen, H. Xia, L. Lu, J.M. Xue, Synthesis of porous hollow $\mathrm{Fe}_{3} \mathrm{O}_{4}$ beads and their applications in lithium ion batteries, J. Mater. Chem. 22 (2012) 5006-5012.

[21] C.N. He, S. Wu, N.Q. Zhao, C.S. Shi, E.Z. Liu, J.J. Li, Carbon-encapsulated $\mathrm{Fe}_{3} \mathrm{O}_{4}$ nanoparticles as a high-rate lithium ion battery anode material, ACS Nano 7 (2013) 4459-4469.

[22] M. Latorre-Sanchez, A. Primo, H. Garcia, Green synthesis of $\mathrm{Fe}_{3} \mathrm{O}_{4}$ nanoparticles embedded in a porous carbon matrix and its use as anode material in Li-ion batteries, J. Mater. Chem. 22 (2012) 21373-21375.

[23] L. Pan , X.D. Zhu, X.M. Xie, Y.T. Liu, Smart hybridization of $\mathrm{TiO}_{2}$ nanorods and $\mathrm{Fe}_{3} \mathrm{O}_{4}$ nanoparticles with pristine graphene nanosheets: hierarchically nanoengineered ternary heterostructures for high-rate lithium storage, Adv. Funct. Mater. 25 (2015) 3341-3352.

[24] L.S. Shen, H.W. Song, G.Z. Yang, C.X. Wang, Hollow ball-in-ball $\mathrm{Co}_{x} \mathrm{Fe}_{3-x} \mathrm{O}_{4}$ nanostructures: high-performance anode materials for lithium-ion battery, ACS Appl. Mater. Interfaces 7 (2015) 11063-11068.

[25] Y. Ma, C. Zhang, G. Ji, J. Y. Lee, Nitrogen-doped carbon-encapsulation of $\mathrm{Fe}_{3} \mathrm{O}_{4}$ for increased reversibility in $\mathrm{Li}^{+}$storage by the conversion reaction, J. Mater. Chem. 22 (2012) 7845-7850.

[26] Y. Wu, Y. Wei, J.P. Wang, K.L. Jiang, S.S. Fan, Conformal $\mathrm{Fe}_{3} \mathrm{O}_{4}$ sheath on aligned carbon nanotube scaffolds as high-performance anodes for lithium ion batteries, Nano Lett. 13 (2013) 818-823.

[27] Y.G. Zhu, J.Xie, G.S. Cao, T.J. Zhu, X.B. Zhao, Facile synthesis of $\mathrm{C}-\mathrm{Fe}_{3} \mathrm{O}_{4}-\mathrm{C}$ core-shell nanotubes by a self-templating route and the application as a high-performance anode for Li-ion batteries, RSC Adv. 3 (2013) 6787-6793.

[28] M. Lübke, N.M. Makwana, R. Gruar, C. Tighe, D. Brett, P. Shearing, Z.L. Liu, J.A. Darr, High capacity nanocomposite $\mathrm{Fe}_{3} \mathrm{O}_{4} / \mathrm{Fe}$ anodes for Li-ion batteries, J. Power Sources 291 (2015) 102-107. 
[29] L. Bai, F. Fang, Y.Y. Zhao, Y.G. Liu, J.P. Li, G.Y. Huang, H.Y. Sun, A sandwich structure of mesoporous anatase $\mathrm{TiO}_{2}$ sheets and reduced graphene oxide and its application as lithium-ion battery electrodes, RSC Adv. 4 (2014) 43039-43046.

[30] M. Ebner, F. Marone, M. Stampanoni, V. Wood, Visualization and quantification of electrochemical and mechanical degradation in Li ion batteries, Science 342 (2013) 716-720.

[31] Z.L. Xua, B. Zhanga, Y. Ganga, K. Caob, M.A. Garakania, S. Aboualia, J. Huanga, J.Q. Huanga, E.K. Heidaria, H. Wangb, J.K. Kim, In-situ TEM examination and exceptional long-term cyclic stability of ultrafine $\mathrm{Fe}_{3} \mathrm{O}_{4}$ nanocrystal/carbon nanofiber composite electrodes, Energy Storage Mater. 1 (2015) 25-34.

[32] Q. Su, D. Xie, J. Zhang, G. Du, B. Xu, In situ transmission electron microscopy observation of the conversion mechanism of $\mathrm{Fe}_{2} \mathrm{O}_{3}$ /graphene anode during lithiation-delithiation processes, ACS Nano 7 (2013) 9115-9121.

[33] A. Magasinki, P. Dixon, B. Hertzberg, A. Kvit, J. Ayala, G. Yushin, High-performance lithium-ion anodes using a hierarchical bottom-up approach, Nat. Mater. 9 (2010) 353-358.

[34] J.Y. Hwang, S.M. Oh, S.T. Myung, K.Y. Chung, I. Belharouak, Y.K. Sun, Radially aligned hierarchical columnar structure as a cathode material for high energy density sodium-ion batteries, Nat. Commun. 6 (2015) 6865/1-9.

[35] H.Y. Sun, M. Ahmad, J. Zhu, Morphology-controlled synthesis of $\mathrm{Co}_{3} \mathrm{O}_{4}$ porous nanostructures for the application as lithium-ion battery electrode, Electrochim. Acta 89 (2013) 199-205.

[36] Y. Waseda, E. Matsubara, K. Shinoda, X-Ray Diffraction Crystallography: Introduction, Examples and Solved Problems, Springer-Verlag Berlin Heidelberg, 2011, p. 127.

[37] C.C. Yec, H.C. Zeng, Synthesis of complex nanomaterials via Ostwald ripening, J. Mater. Chem. A 2 (2014) 4843-4851.

[38] H.Y. Sun, Y.L. Yu, J. Luo, M. Ahmad, J. Zhu, Morphology-controlled synthesis of ZnO 3D hierarchical structures and their photocatalytic performance, CrystEngComm 14 (2012) 8626-8632.

[39] W.J. Zhang, X.J. Li, R.T. Zou, H.Z. Wu, H.Y. Shi, S.S. Yu, Y. Liu, Multifunctional glucose biosensors from $\mathrm{Fe}_{3} \mathrm{O}_{4}$ nanoparticles modified chitosan/graphene nanocomposites, Sci. Rep. 
5 (2015) 11129/1-9.

[40] X.F. Meng, Y.L. Xu, X.F. Sun, J. Wang, L.L. Xiong, X.F. Du, S.C. Mao, Graphene oxide sheets-induced growth of nanostructured $\mathrm{Fe}_{3} \mathrm{O}_{4}$ for a high-performance anode material of lithium ion batteries, J. Mater. Chem. A 3 (2015) 12938-12946.

[41] H. Xia, Y.H. Wan, G.L. Yuan, Y.S. Fu, X. Wang, $\mathrm{Fe}_{3} \mathrm{O}_{4} /$ carbon core-shell nanotubes as promising anode materials for lithium-ion batteries, J. Power Sources 241 (2013) 486-493.

[42] C.S.S.R. Kumar, Raman Spectroscopy for Nanomaterials Characterization, Springer-Verlag Berlin Heidelberg; 2012, p.392.

[43] J.S. Chen, Y.M. Zhang, X.W. Lou, One-pot synthesis of uniform $\mathrm{Fe}_{3} \mathrm{O}_{4}$ nanospheres with carbon matrix support for improved lithium storage capabilities, ACS Appl. Mater. Interfaces 3 (2011) 3276-3279.

[44] L. Li, T.T. Wang, L.Y. Zhang, Z.M. Su, C.G. Wang, R.S. Wang, Selected-control synthesis of monodisperse $\mathrm{Fe}_{3} \mathrm{O}_{4} @ \mathrm{C}$ core-shell spheres, chains, and rings as high-performance anode materials for lithium-ion batteries, Chem. Eur. J. 18 (2012) 11417-11422.

[45] G.Y. Huang, S.M. Xu, S.S. Lu, L. Li, H.Y. Sun, Micro-/nanostructured $\mathrm{Co}_{3} \mathrm{O}_{4}$ anode with enhanced rate capability for lithium-ion batteries, ACS Appl. Mater. Interfaces 6 (2014) 7236-7243.

[46] D. Andre, M. Meiler, K. Steiner, Ch. Wimmer, T. Soczka-Guth, D.U. Sauer, Characterization of high-power lithium-ion batteries by electrochemical impedance spectroscopy. I. Experimental investigation, J. Power Sources 196 (2011) 5334-5341.

[47] H.Y. Sun, Y.G. Liu, Y.L. Yu, M. Ahmad, D. Nan, J. Zhu, Mesoporous $\mathrm{Co}_{3} \mathrm{O}_{4}$ nanosheets-3D graphene networks hybrid materials for high-performance lithium ion batteries, Electrochim. Acta 118 (2014) 1-9.

[48] J. Mujtaba, H.Y. Sun, G.Y. Huang, Y.Y. Zhao, H. Arandiyan, G.X. Sun, S.M. Xu, J. Zhu, $\mathrm{Co}_{9} \mathrm{~S}_{8}$ nanoparticles encapsulated in nitrogen-doped mesoporous carbon networks with improved lithium storage properties, RSC Advances 6 (2016) 31775-31781.

[49] Z. Liu, X.Y. Yu, U. Paik, Etching-in-a-box: a novel strategy to synthesize unique yolk-shelled $\mathrm{Fe}_{3} \mathrm{O}_{4} @$ carbon with an ultralong cycling life for lithium storage, Adv. Energy Mater. 6 (2016) $1502318 / 1-5$ 


\section{Figure Captions}

Fig. 1. $\mathrm{XRD}$ pattern of the as-prepared sample and standard pattern of $\mathrm{Fe}_{3} \mathrm{O}_{4}$ phase.

Fig. 2. FESEM images of the $\mathrm{Fe}_{3} \mathrm{O}_{4}$ microflowers with different magnifications.

Fig. 3. (a-e) TEM images of $\mathrm{Fe}_{3} \mathrm{O}_{4}$ microflowers, with the inset in (d) showing the SAED pattern. (f) is HRTEM image of a single nanoplate from the $\mathrm{Fe}_{3} \mathrm{O}_{4}$ microflowers.

Fig. 4. (a) XPS survey spectra of $\mathrm{Fe}_{3} \mathrm{O}_{4}$ microflowers, (b, c) high-resolution XPS spectra of the $\mathrm{Fe}$ 2p and $\mathrm{O}$ 1s regions, respectively, (d) Nitrogen adsorption-desorption isotherms and corresponding pore size distribution curve (inset) of the $\mathrm{Fe}_{3} \mathrm{O}_{4}$ microflowers.

Fig. 5. Electrochemical performance of $\mathrm{Fe}_{3} \mathrm{O}_{4}$ microflowers: (a) CVs at a scan rate of $0.5 \mathrm{mV} \mathrm{s}^{-1}$ between 0.05 and $3 \mathrm{~V}$, (b) galvanostatic charge/discharge voltage profiles for the first three cycles between 0.05 and $3 \mathrm{~V}$ versus $\mathrm{Li} / \mathrm{Li}^{+}$at a current density of $100 \mathrm{mAg}^{-1}$, (c) cycling performance of $\mathrm{Fe}_{3} \mathrm{O}_{4}$ microflowers (red lines) and $\mathrm{Fe}_{3} \mathrm{O}_{4}$ microspheres (black lines) electrodes at a constant current rate of $100 \mathrm{mAg}^{-1}$ between 0.05 and $3 \mathrm{~V}$, and (d) rate capability of $\mathrm{Fe}_{3} \mathrm{O}_{4}$ microflowers (red lines) and $\mathrm{Fe}_{3} \mathrm{O}_{4}$ microspheres (black lines) electrodes at various current rates between $50 \mathrm{mAg}^{-1}$ and $1000 \mathrm{mAg}^{-1}$. 


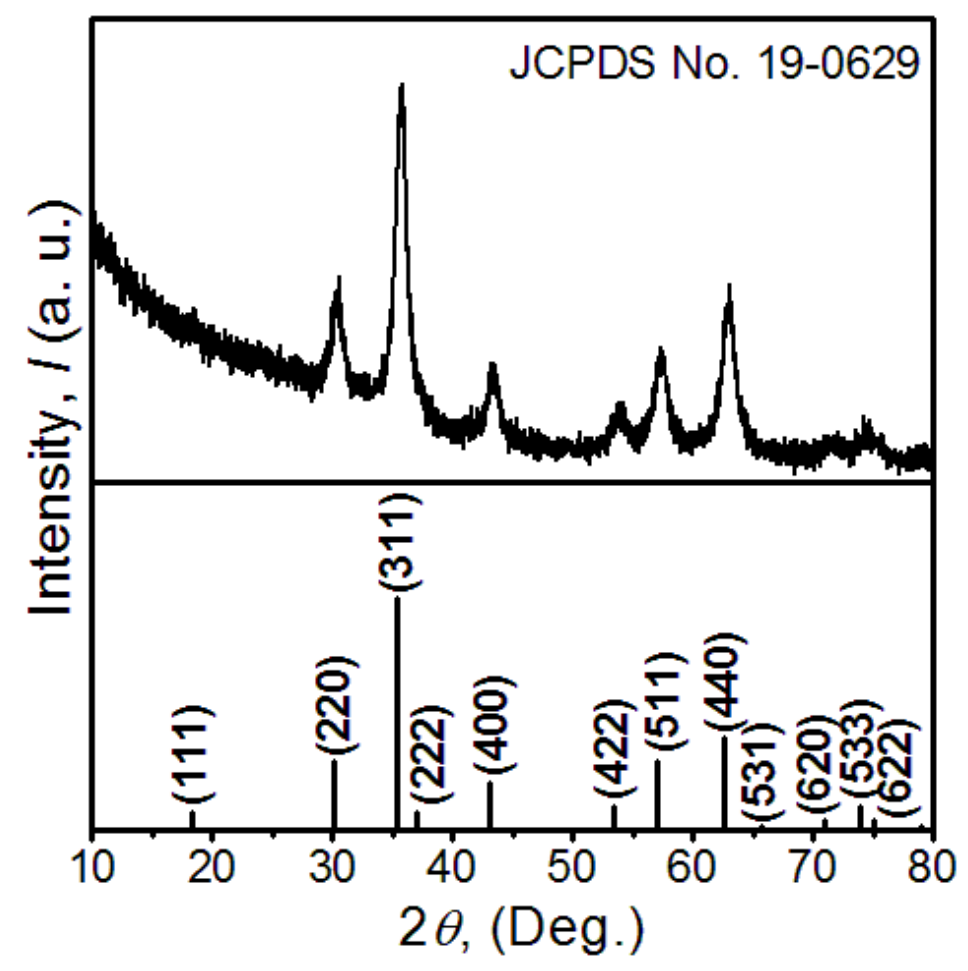

Fig. 1. 


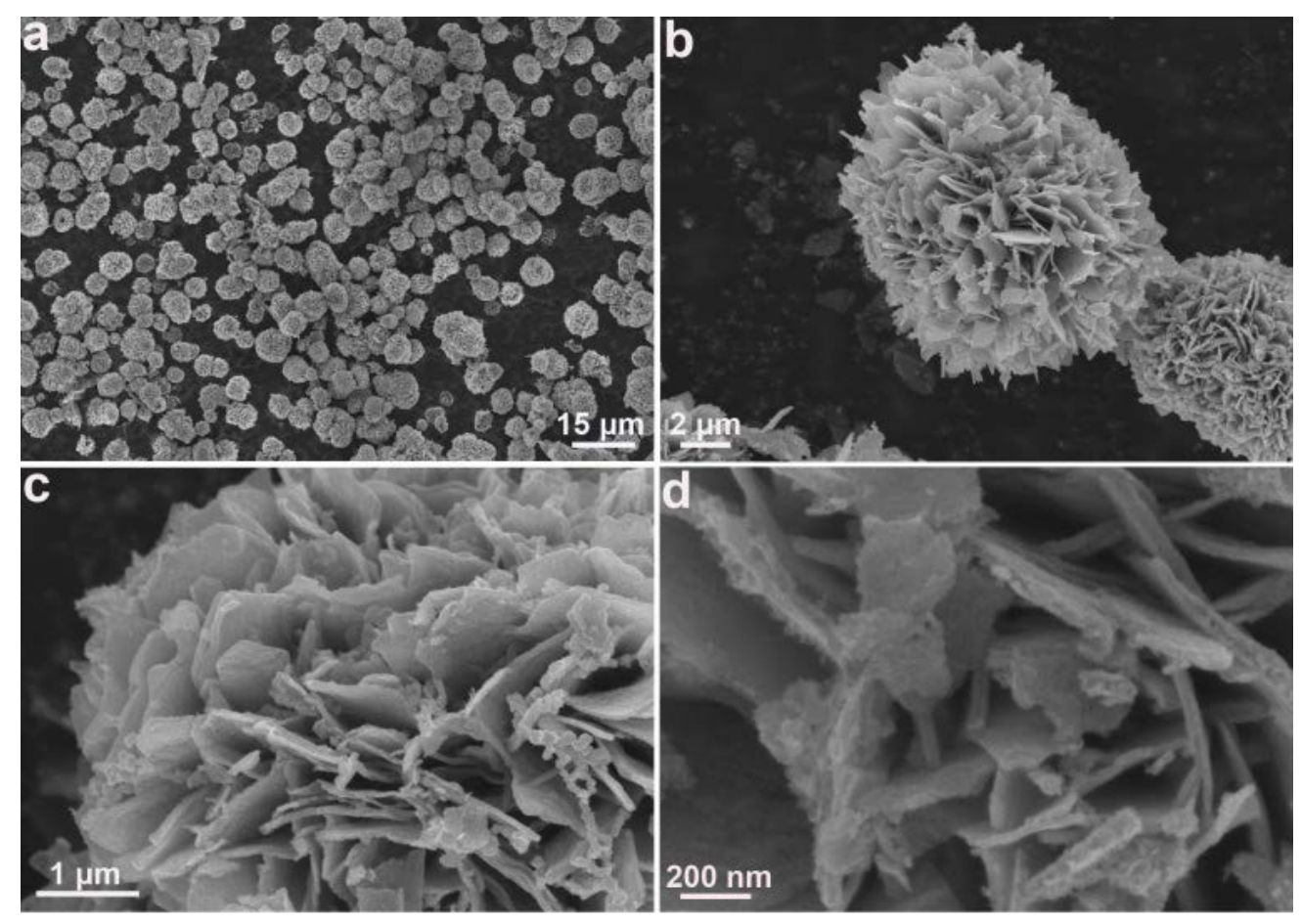

Fig. 2. 


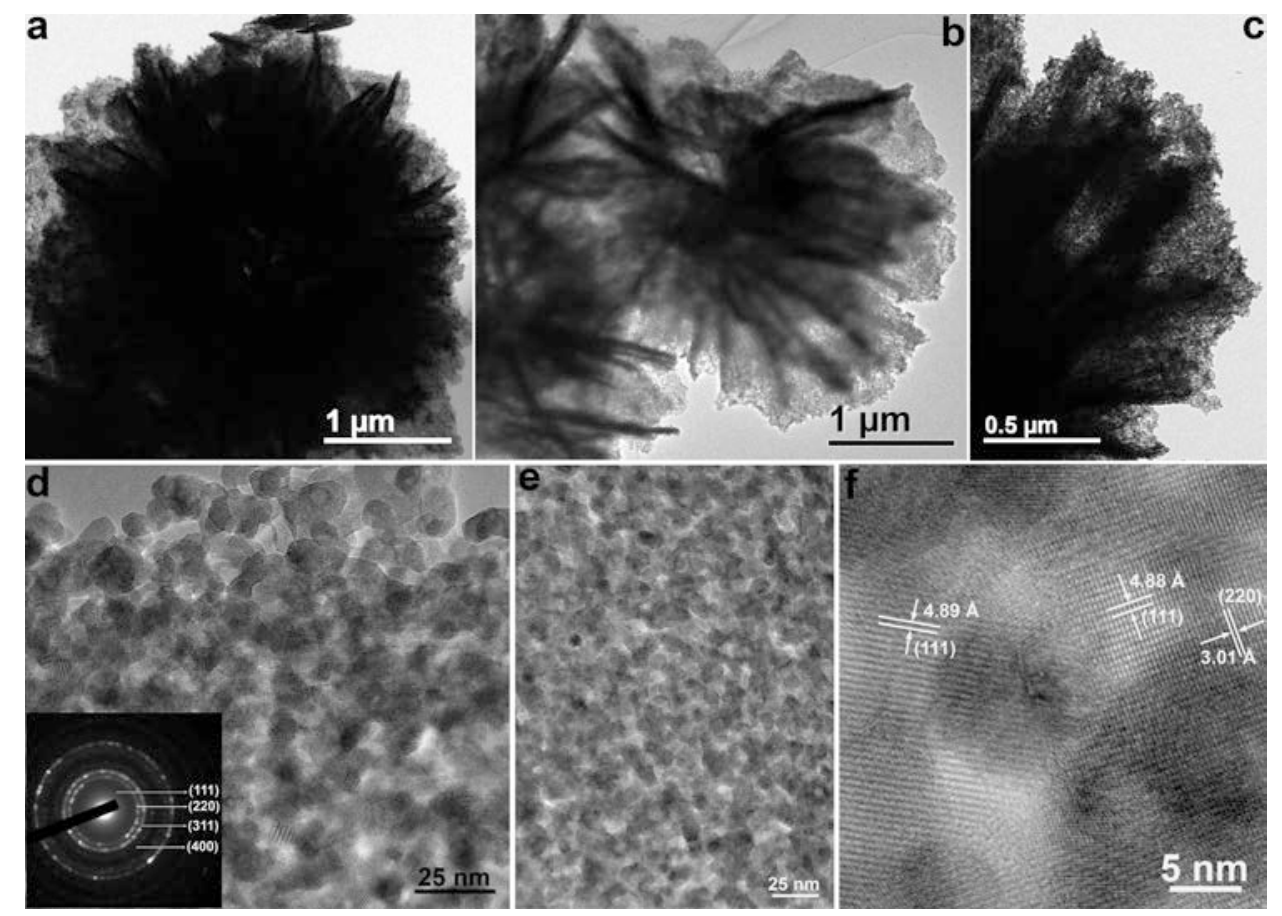

Fig. 3. 

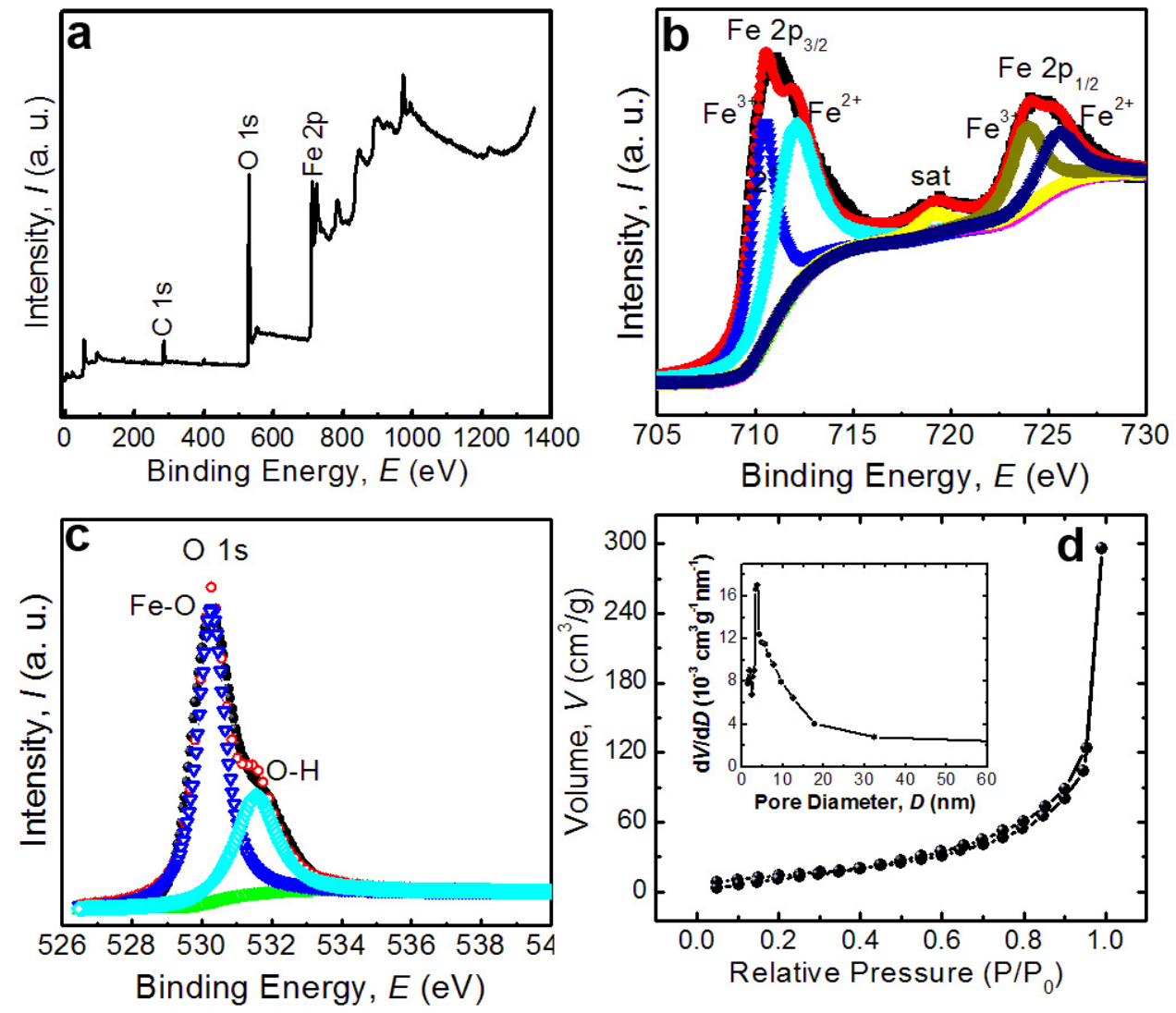

Fig. 4. 

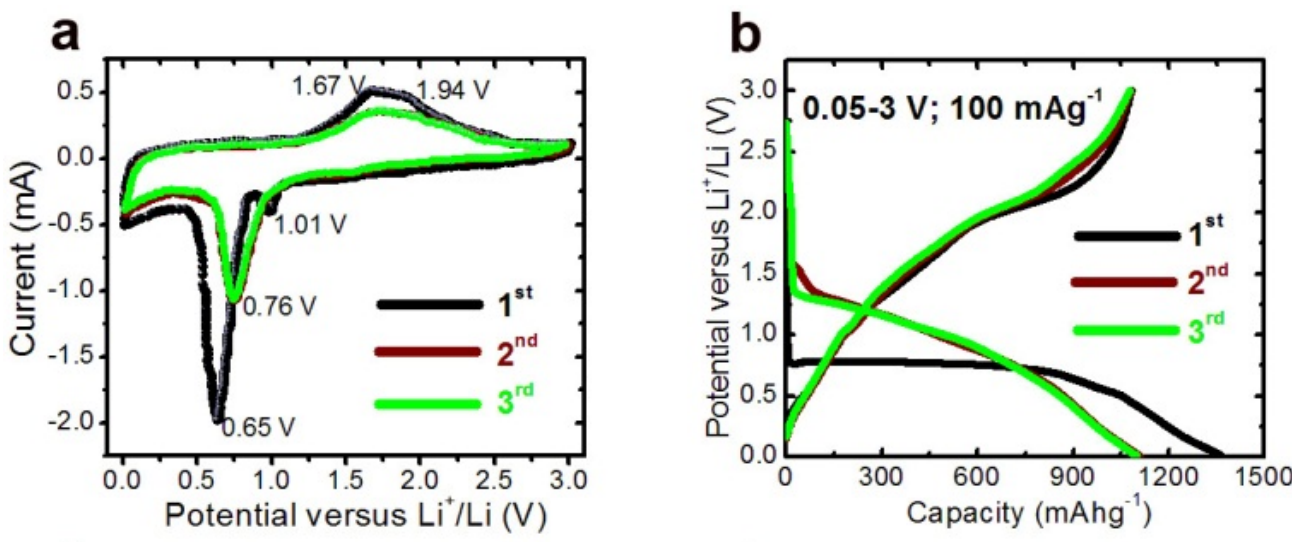

C

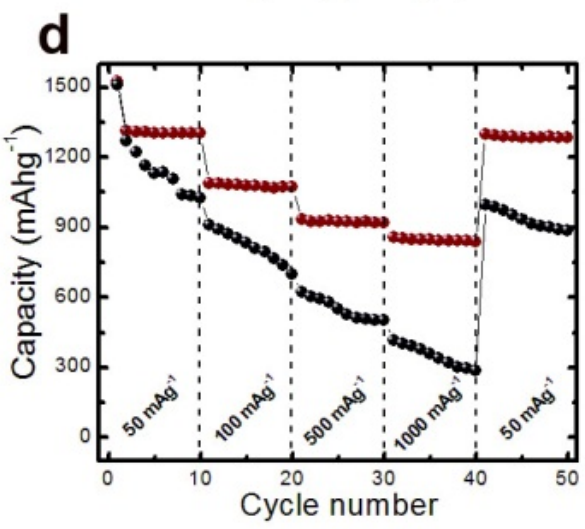

Fig. 5. 